\title{
Obituary
}

HORMONE

RESEARCH IN

PADIATRICS
Horm Res Paediatr 2017;87:423-424

DOI: $10.1159 / 000476013$

Published online: May 29, 2017

\section{Juan Jorge Heinrich, MD, PhD, 1937-2016}

Dr. Juan Jorge Heinrich passed away in Buenos Aires on August 26th, 2016, surrounded by his family and their love, and lauded by an outstanding number of remembrances. His generosity positively influenced the lives and careers of countless pairs and trainees.

Born in Breslau (Germany at that time, today the Polish city of Wrocław), he moved with his family to Argentina as a very young child. He studied medicine, obtained his MD degree from the University of Buenos Aires, and became interested in research soon afterwards. He subsequently received a fellowship of CONICET, the National Research Council of Argentina, and a scholarship of the Swiss government. He moved to Zurich, where he trained with Prof. Andrea Prader, and then to Hamburg, with Prof. Jürgen Bierich. Back in Argentina, he obtained a position at the Division of Endocrinology, Buenos Aires Children's Hospital (Hospital de Niños Ricardo Gutiérrez), chaired by Dr. Martín Cullen. Then, an emerging group, including Drs. César Bergadá and Marco Rivarola, enthusiastic and engaged in experimental and clinical research, welcomed Dr. Heinrich into its midst. His $\mathrm{PhD}$ thesis, presented at the University of Buenos Aires, was based on his work on "Steroid induced sterility: the action of sex steroids on the maturation of the genital tract in the rat." Subsequently, Dr. Heinrich focused on normal growth and its disorders. He created the "Centre of Studies of the Pituitary Hormones" (in Spanish, CETHIP) to-

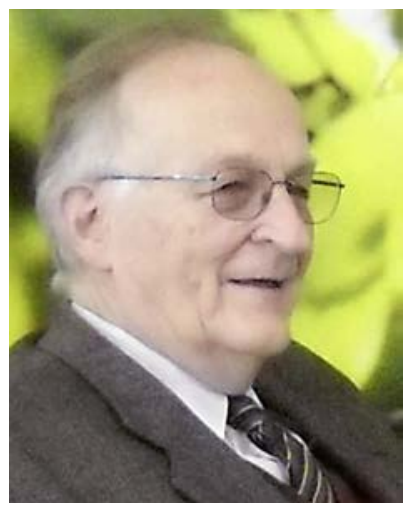

Dr. Juan Jorge Heinrich

gether with Drs. Bergadá, Cullen, Palladini, Dellacha, and Domínguez, a pioneer in the treatment of children with short stature due to hypopituitarism in Argentina and Latin America. At the Division of Endocrinology and CEDIE (Centre for Research in Endocrinology) of Buenos Aires Children's Hospital, he led the working group on "Growth and Development" for many years, reaching the highest research quality standards, with accomplishments that deserved publication in the New England Journal of Medicine.

Dr. Heinrich never left the Buenos Aires Children's Hospital, where he successively served as residents' tutor, Secretary of the Teaching and Research Committee, Chief 
of the Endocrine Laboratory Section, and Chief of the Division of Endocrinology. Passionate about teaching and mentoring young professionals, he was Professor of Paediatrics and Director of the Postgraduate Career in Paediatric Endocrinology at the University of Buenos Aires. He contributed to the formation of several generations of physicians, pediatricians and pediatric endocrinologists. Dr. Heinrich received several awards for his achievements as a pediatrician, researcher, and teacher. He was President of the Sociedad Latinoamericana de Endocrinología Pediátrica (SLEP) and also a member of the Editorial Board of Hormone Research in Paediatrics.
Beyond his professional qualities, Dr. Heinrich will be remembered for his generosity, ethical principles, and being an excellent person. Hardworking, always inquisitive, and devoted to serve others, he was tireless in helping patients, students, and young colleagues. Giving, rather than taking, characterized his everyday deeds. When he formally retired, he left a space without any ego to those who followed. Not requiring anything in return, he continued to share his experience when asked, and he remained generous.

Ignacio Bergadá, Buenos Aires Ana Keselman, Buenos Aires Rodolfo Rey, Buenos Aires 